\title{
Modern Desires, Knowledge Control, and Physician Resistance: Regulating Ayurvedic Medicine in Nepal
}

\author{
Mary M. Cameron
}

\begin{abstract}
Forms of medical regulation in Nepal are shown to limit health knowledge transmission in the name of protecting the people from health care providers both familiar and trusted. Within the last four years Nepal's Ministry of Health implemented controversial legislation requiring Ayurvedic medical practitioners to register with the government in order to practise medicine and to prepare plant-based medications. Traditional practitioners find the age and lineage requirements for those not holding medical certification in Ayurveda potentially devastating to their profession, and they have launched an active campaign resisting the new professionalisation requirements. These actions can be seen to result from the convergence of a rising modern Nepali state bureaucracy, the people's desire for a country free of high rates of morbidity and mortality, and the powerful ideology of Western-based health care modernisation guiding health development. I draw on recent research in Kathmandu and in two rural communities to summarise the role of Ayurveda in Nepal's health care, to analyse the politics behind the legislation and the traditional healers' response, and finally to suggest the legislation's impact on health care.
\end{abstract}

\section{Keywords}

Ayurveda, Nepal, medical regulation and politics, knowledge transmission, traditional practice

\section{Introduction: Local plants and medical knowledge}

In this article, I attempt to explain how one South Asian country's pursuit of modernity has resulted in forms of medical regulation that in effect limit health knowledge transmission in the name of protecting the people from health care providers both familiar and trusted. Within the last four years Nepal's Ministry of Health, following the lead of the Ayurvedic Medical Council, implemented legislation that requires Ayurvedic medical practitioners to register with the government and that prohibits those without formal credentials to prepare the plant-based medications common to Ayurvedic treatment. These incongruous actions, I believe, are best understood as resulting from the convergence of a rising modern Nepali state bureaucracy, the people's desire for a country free of high rates of morbidity and mortality, and the powerful ideology of Western-based health care modernisation guiding 
health development. Significantly, this convergence occurs parallel to the rise of environmental conservation efforts that themselves lend discursive constructs of people and plant relationships to health care development. Thus, shifting but influential new dichotomies of rural and urban locations emerging from these health-related projects are strategically deployed by competing interests in crafting a new medical regime in Nepal. The result is a struggle over medical knowledge-its transmission, its legitimation, and its power in society.

To understand the processes above that have led to the paradoxical medical regulation, I draw on recent research in Kathmandu and its environs, and in two rural communities, to examine the role of Ayurveda in Nepal's health care development. Specifically, I will analyse the politics and ideology behind the legislation and describe how the traditional healers have responded to the new regulatory policy, as this occurs within the context of the medical community's debate on the role of the government in health care resources distribution. Finally, I will suggest what might be the impact of such legislation on health care to potentially limit medical pluralism.

Nepal's ethnic and caste diversity belies remarkably similar relationships people have to plant life economically, ritually, and medically. Skilled artisans craft tools from wood, weave baskets from bamboo, and fire clay pots under mounds of smoldering rice and wheat stalks. Farming families grow crops for subsistence and selectively cut branches of trees and shrubs for fuel and fodder for their domesticated animals. Hindu deities are embodied in various plants, and plants of many kinds are important ritual elements for Hindus and Buddhists alike. In their lifetimes, people develop deep knowledge of the plants that comprise their environment and they apply that knowledge in everyday life. When the daily routine is disrupted by illness, people again seek the plants. They carefully select and pick the roots, leaves, stems, flowers, bark, and seeds of familiar medicinal plants, jadibuti, (literally 'protective entities from roots') to cure a wide range of illnesses. Hindu and Tibetan based traditional medical systems, Ayurveda ${ }^{1}$ and Amchi respectively, both use medicinal plants to treat illness and, in the case of Ayurveda, to restore health by rebalancing the body's humors. ${ }^{2}$

\footnotetext{
${ }^{1}$ Approaches to healing that are considered Ayurvedic will be delineated in a later section, to show both their relationship to each other as well as their uniqueness, and to provide an albeit brief description of the kinds of Ayurvedic medicine practised in Nepal. That section, however, will not address the broader discursive treatments of Ayurveda historically and regionally, such as how Ayurvedic medicine has come to be called 'Indian medicine' within and outside of India.

2 The raising of animals and the consumption of meat also have economic, medical and ethnic importance throughout Nepal's diverse populations, but will not be addressed here.
} 
Even with its rich jadibuti knowledge, however, the country suffers from high rates of infant, child, and maternal mortality, as well as many kinds of preventable morbidity. Health care development in Nepal struggles to reverse this suffering.

It is not an overstatement to say that bikas (development) stands alongside dharma and karma as powerful ideologies that the people of Nepal embrace. The failures of broad-based national development notwithstanding, the people of Nepal continue to desire a modern country embodying values of progress that include a more effective pluralistic health care system. State health officials have sought to gain people's support in eradicating illness and suffering by linking their goals to the national quest for a developed, modern state. To that end, and with funding from numerous international and multinational development organisations, the state has focused a majority of its efforts on the widespread distribution and availability of biomedically-based health resources. In the eyes of many and in the words of Dr Lokendra Man Singh, Nepal's leading figure in Ayurvedic medicine until his death two years ago, Ayurvedic medicine has been neglected in the drive toward biomedical proliferation:

The country has yet to fully recognize the role of Ayurvedic and other traditional medical systems for the national health care system. Despite its long history, in the last few decades [Ayurveda] has officially been supplanted by another medical system. Resources have been directed to manufacturing allopathic medicines. Policies, planning and other activities are still inconsistent. Rules and regulations are more regulatory instead of facilitating. Inadequate budget, bias in prioritizing [the] country's resources, lack of sound interrelationship amongst [the] public, development partners, I/NGOs and private organizations and institutions to develop policies, planning, research work and services activities are plaguing the development of Ayurveda and other traditional medicines. Clear and consistent policy on TM and its role in the national health care system is very vital. It has been felt that excessive reliance on formal western medicine is inadequate to reaching full health care to the people. ${ }^{3}$

As Dr Singh explains, health officials have included Nepal's traditional medical practices in the nation's health policies. However, along with biomedical technology and training, practices associated with a modern health care bureaucracy have also grown with the embrace of biomedical science, and have consequentially entered the political arena. As a result, the state, while including traditional medicine in its policies, has also increasingly limited who qualifies as its legitimate practitioners. In so limiting, I argue, the state medical bureaucracy goes beyond recreating an opposition between traditional and

\footnotetext{
${ }^{3}$ Singh and Khaniya n.d.
} 
modern medicine by effectively erecting barriers around forms of knowledge transmission in a manner that is contrary to values of progress. Thus the issue in question is the power of the state not only to contribute to discursive renderings of traditional and modern but effectively to create permanent impediments to knowledge transmission and medical practice in the name of western science. This article as such, articulates with the recent concerns of Ernst and others studying medical pluralism in South Asia, that scholars address directly the power of biomedicine in the hands of the state and in global public health agendas, rather than uncritically accepting biomedicine as only one product in the 'medical market place' of patient consumer choice ${ }^{4}$ and in medical education. ${ }^{5}$ As we will see, medical regulation in Nepal has followed what Lock and Nichter identify as biomedicine's 'homogenising' and 'rationalising' impact on national health policies, going far beyond simple medical syncretism. ${ }^{6}$

In this article, I focus on Ayurvedic medicine to describe how the convergence of health care modernisation that follows biomedical standards, and the rise of a modern Nepali state bureaucracy, have led to new governmental regulation of Ayurveda with potentially profound consequences. The deployment of 'scientific vocabularies' by government officials that articulate the alleged risks to a vulnerable population of unprocessed plants in the hands of unprocessed knowledge has made possible an unprecedented governmental regulation of Ayurvedic medicine that advances the profession through formally-trained practitioners only. ${ }^{7}$ Through the bureaucratic strategy of standardised medical licensing, Ayurvedic medicine is being carved out as a realm of practice legitimately regulated by the Ministries of Health and Education with their power to use and confer new, modern authority. What is potentially sacrificed is a fluid (and some would say ancient) tradition of medical education found throughout Nepal's urban and rural communities, and the broad and widespread lay use of medicinal plants. These actions, however, are not proceeding unchallenged by traditionally-trained physicians.

Raised in rural and semi-urban environments, lay people have extensive knowledge of jadibuti which they pass on to their children and grandchildren, and some enhance their experiential knowledge in Ayurvedic medicine by

${ }^{4}$ Ernst 2002, p. 4.

5 Following convention as summarised by the World Health Organization, biomedicine in this article refers to the broad category of medical practice that is sometimes called allopathic medicine, Western medicine, scientific medicine, or modern medicine (WHO 2001, p. 1). For specific examples related to Ayurvedic medicine in South Asia, see Bode 2006 on the narrowing of Ayurvedic pharmaceutical choices, and Nisula 2006 on the use and justification of biomedical technology by Ayurvedic physicians. See also Khan 2006 on early twentieth-century policies first articulating biomedical supremacy in India.

${ }^{6}$ Lock and Nichter 2002, p. 10.

7 Anderson 2003, p. 29. 
becoming students in formal medical educational institutions in Nepal and abroad, eventually to become baidya (Ayurvedic physicians, commonly called vaid in India) in villages and cities. Within a second educational tradition, urban sons and daughters of lineage healers continue the family tradition by committing to long years of apprenticed learning alongside fathers, uncles, and grandfathers in clinics nearby (and occasionally within) the family living space. Finally, a third and similar non-formal learning tradition involves those who supplement their experiential and family knowledge of Ayurvedic medicine and medicinal plants with informal education from other learned healers who are not relatives, to gradually earn reputations as effective and compassionate healers. These three groups of Ayurvedic practitioners have worked alongside one another for decades, even centuries, providing health care to urban and rural Nepalis alike. Now, however, their professional relationships are being fundamentally altered due to recent legislation mandating medical licensing.

The use of plants in healing, following broad Ayurvedic principles, finds enthusiastic followers among urban and rural Nepalis, and casual conversation and official discourse about medicinal plants are readily generated in a variety of places. ${ }^{8}$ In addition to family and clinical healing interactions, medicinal plant conservation is locally engaged in everyday practices common to Nepalis, as well as within specific engagements with family-trained and academicallytrained doctors, and finally by government and non-government organisations working to protect non-timber forest products. A disjuncture between local and state conservation practices, however, noted for some time by scholars working in Nepal, ${ }^{9}$ finds a not unsurprising parallel in the government's westernisation-driven development of health care in the country, where government health management at the centralised state level reduces local level control. Dr Singh describes the local articulation of Ayurveda in Nepal in the face of globalisation forces: 'Traditional medicine is based on local talents, local resources, and local popularity. Globalisation should not try to undo this phenomenon'. ${ }^{10}$ Nonetheless, in the case of Ayurvedic medicine, the Department of Ayurveda and the Ayurvedic Medical Council (both within the Ministry of Health) have progressively removed management from local communities. The licensing regulations discussed here-which are essentially educational regulations - are one decisive step in that direction.

I carried out the ethnographic research on which the analysis relies in urban and rural Nepal from 1998 to 2005, and I also include some early research

\footnotetext{
${ }^{8}$ Ayurvedic medicines also may contain animal materials and metals, but these ingredients are minor in comparison to plant ingredients and are not discussed here.

9 See Des Chene 1996 and Shrestha 1995.

${ }^{10}$ Singh n.d., p. 3.
} 
findings from 1983. The focus on medical licensing is part of a larger study examining the modernisation of Ayurveda in Nepal. Observations were made in Ayurvedic hospitals, clinics, health posts, classrooms, and pharmacies, and guided conversations and structured and unstructured interviews were conducted with female and male practitioners, health administrators, and patients and their families, primarily in the three cities of Kathmandu Valley (Kathmandu, Bhaktapur, and Patan), in Dang District Ayurvedic Hospital, and in rural communities in far western Bajhang District. Based on nearly a decade of conversations with doctors, patients, government officials, and educators, I recognise that a central dilemma in health care development that takes seriously Nepal's medical traditions is whether the country can follow a path of progress without abandoning Ayurveda or subsuming it into a single, monolithic biomedical system.

This dilemma is borne out in the government's paralysis on many aspects of Ayurvedic development, such as infrastructure, education, and medical supplies, while simultaneously proclaiming Ayurveda's culturally significant role in primary health care (stated in the Ministry of Health's National Health Policy 1991, Second Long Term Health Policy 1997-2017, and the Ninth and Tenth Five Year Health Plans 1996-2001 and 2002-2007). The paradoxically stringent regulation of Ayurvedic medicine can nonetheless be understood as a result of the converging histories of Ayurvedic medical evolution, the ascendancy of biomedical science in the country, a strong desire for a modern and developed nation and a country free of high rates of morbidity and mortality (particularly infant, child, and maternal mortality), and the exigencies of democratic party politics, as all these factors play out in discursively constructed rural and urban sites.

\section{Rural and urban positions}

Nepal is one of the smallest and poorest countries in South Asia, and is one of only a handful of countries in the world never colonised. Though rapidly modernising in some sectors, ${ }^{11}$ and with a large urban influx of refugees from the recently ended rural Maoist conflict, Nepal retains visibly agrarian roots. Such roots may be partly responsible for the continued preference for plantbased medicines like Ayurveda. Many people believe Ayurveda provides a fundamentally sound theory of health and illness that links diet, 'ecology', daily activities, social milieu, and mental attitude, and one that is supported by

11 Liechty 2002. 
people's extensive knowledge of medicinal plants and their uses. As Dr Singh states in an unpublished paper on Ayurveda and culture in Nepal:

The objective of Ayurveda is to achieve the highest goal of life, the inner and outer dynamic harmony. The dimensions of health are defined as bodily, sensorial, mental, and spiritual health. All measures such as daily routines, lifestyle, food, herbs, treatments, and other guidelines are used to achieve a state of total health and a quality of life that is productive and free from disease. ${ }^{12}$

Furthermore, medicinal plants are part of social networks; Nepalis generously share their knowledge of plants with others - family, neighbours, and foreigners. Indeed, they honour healing plants as a gift from the gods.

Rural landscapes play a second role in health care in Nepal. Health care discourse frames urban and rural locations in ways that increasingly polarise the landscape of patients and healing, and that classifies and ranks health care practices and people. ${ }^{13}$ Urban and rural healing sites become inscribed with competing and shifting values as they are drawn into the struggle over health care resources and professional legitimacy. The meanings associated with space divided in this way become part of the language with which Ayurveda is modernised. The current and entirely urban-based effort to regulate and professionalise Ayurvedic medicine by the health care bureaucracy positions the rural as a place where important medicinal plants grow, but also marks the rural as a remote place where traditionally-educated practitioners treat the ill with inadequate and unregulated medical knowledge. Contributing to the characterisation of rural Nepal as a disorderly place is the state's own failure to regulate the flow of medicinal plants across its national borders and the environmental complications derived from illegal harvesting and trade.

Furthermore, as we will see below, health care administrators relegate village practitioners' knowledge to an inferior form of healing practice lacking modern, formal training in an urban Nepali or Indian Ayurvedic college or university. To be clear, though, it is not the medical 'system' itself, Ayurveda, that is problematic but rather the lack of rational structure around its transmission that is at issue, combined with the modern role health administrators see themselves playing as protectors of the public's health and as administrators of large budgets.

However, an easy dichotomy of traditional/rural/undeveloped versus modern/urban/developed becomes increasingly untenable — and in fact, reversedwhen we consider the work and words of environmentalists and Ayurvedic physicians. Contrasting with the health care bureaucracy's view of an unregu-

12 Singh and Khaniya n.d., p. 1.

13 Pigg 1992. 
lated and disorderly rural is the perspective of those wishing to develop Ayurvedic medicine on the wave of global interest in indigenous knowledge (in particular medical knowledge), such as environmental NGOs seeking new ways to protect Himalayan floral biodiversity. As in many so-called developing countries, environmental conservation in Nepal is an effort jointly approached by government agencies, NGOs and INGOs. ${ }^{14}$

What is unique about the practices of conserving medicinal plants in Nepal is the involvement of the Ayurvedic medical community, whose livelihood is directly impacted by the quality and quantity of medicinal plants in the country. ${ }^{15}$ As the Ayurvedic community attempts to educate the public and policymakers about best practices of harvesting and preparing medicinal plants according to Ayurvedic theory, the scientific community advances best practices supported by modern ecological principles that do not always mirror those of the Ayurvedic community. During an interview with me at his home cum clinic in 2000 when he was 94, Siddhi Gopal Baidya, a former royal physician, talked of his efforts to persuade government officials even up to a former Prime Minister, Krishna Prasad Bhattarai, about the need to protect medicinal plants. He feels that the Ayurvedic community, and not environmentalists, should oversee the protection and sustainable use of medicinal plants that are an integral part of Ayurvedic medical practice and that they know well.

I am very concerned about the loss of these plants. I have been talking with some of the important leaders. Do you know Krishna Prasad Bhattarai? He is the former Prime Minister and is also a prime minister candidate from one of the major parties. I have been talking with these leaders and urging them to do something about the diverse medicinal flora. I also told them that if they give [the management of plants] to us, we would protect them because we know what they are and their value.

Even with the urging of the Ayurvedic medical community and the availability of modern ecological knowledge, though, the government's commitment to sustainable harvesting of plants used as medicine in Ayurveda is in the eyes of many inadequate. Dr N. N. Tiwari, a respected Ayurvedic physician best

\footnotetext{
${ }_{14}$ The main environmental players in Nepal are the Ministry of Forestry and Soils Conservation, the World Wildlife Fund, International Centre for Integrated Mountain Development (ICIMOD), International Development Research Center, Canadian Centre for International Studies and Cooperation (CECI), smaller agencies funded through international donations, and academic departments at Tribhuvan University.

${ }^{15}$ Estimates of non-timber forest products (NTFP) exportation, which is mainly comprised of medicinal and aromatic plants (MAPS) range from official estimates of $\$ 4.7$ million in royalty to nearly $\$ 27$ million. One estimate places the annual export value to India alone at $\$ 18$ million (Kanel 2000).
} 
known for his botanical knowledge, described for me the economic and medical consequences of the Nepali government's failure to protect its plant wealth.

We are very rich in biodiversity, especially the diversity in plants. We are ranked
27 th in the world in biodiversity. But we have to see it as a potential for providing
revenue for us, as a major economic resource of the country. We are said to be rich
in water resources but then we must buy a bottle of mineral water for 20 rupees.
Similarly, we are rich in jadibuti but the government has no interest in developing
their production. [Only with great] difficulty, a Vaidyakhana at Singha Darbar
has been established. The local manufacturing units of Ayurvedic drugs in Nepal
fulfill only $15 \%$ of the internal demand while the remaining $85 \%$ is imported
from India. The maximum portion of our medicine is from the Dabur Company.
Dabur Nepal also produces the maximum portion of the finished products that
are exported. This company does not belong to the government but to the private
sector. ${ }^{16}$

Formally-trained Ayurvedic physicians, like environmentalists and lay urban elites, regard rural people's plant knowledge as superior even to their own botanical knowledge. They regularly complain that new graduates in Ayurveda lack the botanical knowledge that rural people and those trained through the traditional lineage system possess. Typical criticism of formal Ayurvedic education centres on insufficient training in medicinal plant identification and preparation, in contrast to informally- and family-trained doctors who acquire extensive plant-based knowledge through their long apprenticeships with family members and other traditional teachers.

One conclusion we can draw from these various contexts is that when it comes to Ayurvedic medicine, rural and urban locations are infused with contradictory meanings and are available to conflicting and powerful interests. ${ }^{17}$ Tracing these discursive framings, then, becomes an important part of understanding health care modernisation's impact on Ayurvedic medical development.

For example, many Ayurvedic physicians I have interviewed express great concern over the deteriorating urban environment. These include Acharya Krishna Bahadur Singh, 82 years old and also a former royal physician, who spoke with me at his home in Kathmandu one morning in 2000 as he delineated the various illnesses afflicting Nepalis today:

There is more pollution of the environment, more dust particles and harmful smoke in the air from the emissions of the vehicles. The land is filled with garbage thrown by everyone. There is also the pollution of sound. Throughout the day in the city areas, you get disturbing noises. ${ }^{18}$

\footnotetext{
${ }^{16}$ Interview with Dr N.N. Tiwari, Kathmandu, 8 November 2000.

${ }_{17}$ For further discussion, see Cameron 2009b, forthcoming.

${ }^{18}$ Interview with Acharya Krishna Bahadur Singh at his home in Chabahil, Kathmandu, 8 July 2000.
} 
For Ayurvedic physicians like Acharya Singh, the rural environment again stands in superior contrast to materialistic, crowded, polluted and imbalanced urban places. Similarly, the current interest in Ayurvedic medicine among urban-educated elites comes from Ayurveda's association with 'nature' rather than its ancient heritage and efficacy. For them, Ayurveda is preferable because it is natural, not because it is traditional; interestingly, the 'traditional' is transformed into the modern through tropes of 'nature'. Further complicating the picture are Ayurvedic physicians who assert Ayurveda is, in fact, modern, as is evident in its universal theory of the body, its continuing popularity over the centuries, and its current global appeal. This kind of fluid circulation of symbols and referents forces us to look beyond the dichotomy of traditional and modern categories that health care administrators may strategically deploy, to broader categories such as knowledge, its transmission, and its regulation as indicators of broad social transformation.

The discourse of medicinal plant conservation, cast in both traditional and modern frames, has become a kind of bridge linking environmental movements and indigenous medical movements. Conservation techniques increasingly deploy both 'traditional' and modern scientific language related to plant and human interfaces, and Ayurvedic medical development includes progressively more focus on the status of medicinal and aromatic plants in the country and their efficacy as evaluated through allopathic medical standards. ${ }^{19}$ Such pharmacological legitimisation concerns practitioners who prefer instead that the state advocate and implement goals of progress that include institutional and human resources development. The regulation of Ayurvedic practice promulgated in the recent legislation described here may in fact disrupt the informal education of healers in villages and cities, and potentially restrict even local people's use of medicinal plants. Thus, the legislation seems to be at odds with other development goals related to people, plants and health in Nepal. Sorting out this paradox requires looking at the historical context of current medical licensing regulations, to which we now turn.

\section{Twentieth and twenty-first century Ayurveda in Nepal}

For at least the past one hundred years and up to the present, Ayurvedic medicine has been one of the most common forms of health care in South Asia; the World Health Organization, without apparent attribution or reference,

19 See Cameron 2009b, forthcoming. 
declares Ayurveda to be the 'national medical system' in Nepal. ${ }^{20}$ The importance of Ayurvedic medicine in Nepal before the middle of the last century is evident in several historical facts. Former baidyas to the Rana courts in Kathmandu have told me in interviews of the support Ranas gave to Ayurvedic medicine. They maintained a group of Ayurvedic family doctors and established important Ayurvedic institutions during their reign. The most well-known of the palace baidyas, Siddhi Gopal Baidya, mentioned earlier, represented the twenty-third generation of lineage practitioners before he died in 2004 at the age of 98. Acharya Krishna Bahadur Singh, who holds a GAMS (Graduate in Ayurveda and Medical Surgery) from Patna, India, and a MAMS (Masters in Ayurveda and Medical Surgery) from Calcutta, worked as the baidya to Dharma Shamshere Rana, a son of Prime Minister Bir Shamshere Rana, and whose lone surviving son and family continue to seek medical care from the ageing Acharya.

After the overthrow of the Ranas and the re-ascension of the Shah ruling lineage, Acharya Singh continued to work occasionally for the royal family through the reign of King Mahendra, who appointed him as the first director of the Department of Ayurveda, as he describes here in 1998:

I treated [King Mahendra] from time to time and afterwards I also undertook a job. I was made the director of the Department of Ayurveda for whole of Nepal. That was why I visited so many other countries. King Mahendra also awarded me the medal of Prabala Gorkha Dakshin Bahu. ${ }^{21}$

Eight generations of baidyas will not end with him, however, for his daughter, Katambari Acharya, is an Ayurvedic physician working as a teacher and physician at Naradevi Teaching Hospital, the main Ayurvedic campus described below.

To continue, Gurkha military units took assigned baidya to England in the first decades of their British employment. In village and urban life, too healing was achieved through people's opportunistic resort to self-cure, and through visits to baidya, herbalists, shamans, Tibetan doctors, wandering ascetics, and priests - a pluralistic healing landscape and a resort pattern typical today that now also includes biomedicine. ${ }^{22}$ Today, a large majority of elderly Nepalis know herbal medicinal preparations and can identify numerous, common medicinal plants. ${ }^{23}$

\footnotetext{
20 WHO 2001, p. 137.

${ }^{21}$ Ordinary Member Fourth Class Order of the Gurkha Right Hand, an honorary medal founded in 1896 and given by Nepal's kings to citizens for meritorious achievement. Interview with Acharya Krishna Bahadur Singh at his home in Chabahil, Kathmandu, 8 July 2000.

22 Adams 1988; Burghart 1984; Parker 1988; Stone 1976, 1986.

23 Cameron 1986; Himalayan Ayurveda Research Institute 1996.
} 
In Nepal, formal Ayurvedic education began with King Chandra Shamshere Rana, who in 1928 established an educational fund for students to be sent to India to study Ayurvedic medicine, under the auspices of Nepal's Rajakiya Ayurveda Vidhyalaya. The students completed their studies in five years and returned to Nepal to inaugurate the Ayurveda Vidhyalaya and Chikitsalaya, later to become Naradevi Ayurveda Teaching Hospital and College in Kathmandu. ${ }^{24}$ Its mission was, and continues to be, to advance the teaching of Ayurvedic medicine and to serve patients free of charge. When Nepal opened its borders to the world in the 1950s following the removal of the Rana rulers and the re-ascension of the Shah lineage, the modern world flowed in. Tourism quickly flourished with the appeal of the ancient temples and magnificent Himalayas, and the contemporary era of bikas (development) began. Among the many implements of modernity the Shah rulers introduced was a strong support for allopathic medicine; according to elder baidya the Shah kings, particularly King Birendra, through the 1970s and 1980s gradually removed Ayurveda from the palace by replacing the physicians with allopathic doctors, and mandating a retirement age of 60 that encompassed virtually all of the Ayurvedic doctors affiliated with the palace.

Pressure to modernise the small, mountainous country was met through the introduction of European health care development in the form of immunisation programmes, public health programmes, the establishment of a world-class biomedical college and auxiliary schools, and a rapidly expanding pharmaceutical industry. ${ }^{25}$ Today, the health and medical systems in Nepal can be grouped into four categories: the home-based system; the faith-healing system; so-called 'traditional medicine' that includes Ayurvedic medicine, homeopathy, Tibetan medicine, and Unani; and, allopathic medicine with its vast network of hospitals, clinics, medical and nursing schools, pharmacies, and practitioners.

In 2002, there were 4,154 allopathic hospitals, health centres, health posts, sub-health posts, and primary health centres, and 277 similar Ayurvedic facilities. There are two regional Ayurvedic hospitals, Naradevi Teaching Hospital and College in Kathmandu, with 100 beds, and Dang Ayurvedic Hospital, with approximately 50 beds; 14 zonal clinic/dispensaries, 50 Ayurvedic health centres, and 211 Ayurvedic clinics. Additionally, there are nearly 40 private drug companies, 275 Ayurvedic drug dispensaries and a semi-autonomous drug research and manufacturing institute called Singh Durbar Vaidyakhana, which is over 350 years old. ${ }^{26}$ Private Ayurvedic drug production

${ }^{24}$ Interview with Shesh Raj Acharya, Superintendent, Naradevi Ayurveda Teaching Hospital, 1999.

${ }^{25}$ Justice 1986.

${ }^{26}$ Nepal Development Forum 2002. 
companies in Nepal include Gorkha Ayurveda and Dabur Nepal, ${ }^{27}$ as well as hundreds of small family Ayurvedic businesses that produce primarily for their communities.

\section{Contemporary Ayurvedic education and practice}

Practitioners of Ayurvedic medicine in Nepal come from different economic and geographical backgrounds, though most of them are from the upper castes. It should be noted that, while the treatment system is available to all, and often free of charge, the social organisation of Ayurveda is not yet egalitarian. More so in the past, yet also true today, Ayurvedic practice reflects social exclusions present in contemporary Nepal that relegate women and dalits to inferior social and educational positions, thus rendering a career in medicine difficult for them. Still, dalit and female healers who have demonstrated skill and knowledge in diagnosis and plant-based healing are sought by sick villagers, and the number of female students currently pursuing degrees in Ayurveda equals those of males.

Colleagues I have worked with include non-literate rural baidya who have extensive knowledge of local medicinal plants and live on the margins of poverty like many of their rural neighbours, and urban physicians with advanced Ayurvedic degrees from India who are successful proprietors of clinics for foreigners during the day and healers at community Nepali clinics during the early evening hours. There are those who work primarily in administration in the Ministry of Health, and those who see patients throughout the day at family-based clinics that may be hundreds of years old. A dalit Ayurvedic physician who hid his caste and studied in India is the subject of a separate article. $^{28}$

The evolution of Ayurvedic medicine has included periods of professionalisation that have accelerated in the modern era with biomedicine influencing the structure of the educational system advanced by the recently deposed Shah rulers. Restructuring of the formal educational system in the second half of the twentieth century, with slogans such as 'education to meet the needs of the people', impacted Ayurvedic medicine. The Sanskrit-based curriculum at

\footnotetext{
${ }_{27}$ Madhu Bajracharya, the son of Manu Bajracharya, a well-known Ayurvedic physician from a Newari lineage and a doctor for many expatriates ill with hepatitis $A$, asserts that modern production can never match the 'natural' and ancient system of pharmacy in Ayurvedic traditional practice, which requires preparing the plants according to astrological and biological rhythms.

${ }^{28}$ Cameron 2009a, forthcoming.
} 
Naradevi Teaching Hospital was changed to a Nepali- and English-based one, ${ }^{29}$ and the four-year degree was forced to become a three-year programme in line with other higher education programmes. The three-year Ayurvedic degree was renamed 'Proficiency in Complementary and Traditional Medicine', dropping the word Ayurveda altogether from the title.

Supervision of the main institution of formal Ayurvedic education, Naradevi Teaching Hospital, was moved from the Ministry of Health to the Institute of Medicine in the Ministry of Education in 1972, when allopathic medicine was introduced as a discipline and a degree programme. From there, Naradevi's medical teaching staff developed and offered a curriculum that contained varying and increasingly allopathic components in what is generally called an integrated curriculum. ${ }^{30}$ The graduate degree in Ayurvedic medicine began in 1972, was stopped five years later in 1977 due to lack of resources, was again restarted in 1987 until 1991, when it was again postponed, then reopened again in 1997-8, admitting 15 students annually. The course of study for the BAMS, Bachelors in Ayurvedic Medicine and Surgery, is five and a half years; it includes one year of clinical rotation, and biomedicine comprises approximately 15 per cent of the curriculum and is the major component of admission prerequisites. Sanskrit language is once again required, though most courses are taught in Nepali and English. A new Ayurvedic medical complex on the Kirtipur campus of Tribhuvan University is near completion after many delays and should open in the next few years, when the staff and students at Naradevi will be relocated to Kirtipur. In addition to the graduate programme, Mahendra Sanskrit University in Kathmandu runs a oneyear certificate course; other lower level programmes for certification of Auxiliary Ayurvedic Workers are reportedly being opened, sometimes without the Department of Ayurveda's approval. ${ }^{31}$

The large gaps of time in which the advanced degree was not offered and the continuous disruption of formal education at all levels in Nepal due to political unrest over the past three decades, have left educators and administrators

29 Ayurvedic education has typically favoured Sanskrit as the language used to read the classic texts. Although these texts are now found translated into other contemporary South Asian and European languages, some programmes still require that students be able to read and comprehend Sanskrit for the purpose of reading the original language of the manuscripts. The BAMS degree from Naradevi requires coursework in Sanskrit language.

30 See Leslie $1976 a, 1976 b$, and 1992.

31 Interview with Bharat Jha, PhD, President of Health Professionals Council, 2000. The regulation of lower level programmes is complicated by the fact that their oversight body, Council for Technical Education and Vocational Training (CTEVT), is under the supervision of the Ministry of Education, and not Health; second, some programmes are set up in remote areas such as Humla and Jumla, making travel there for regulatory purposes impractical and difficult. 
feeling a keen pressure to catch up with the other countries of South Asia. Currently, some Ayurvedic faculty members are studying for advanced degrees in obstetrics and pancakarma therapy in India, and will return to teach and to treat patients at Naradevi. ${ }^{32}$

As formal professional institutions were evolving in the second half of the twentieth century and the beginning of the twenty-first century, what was happening to the largest group of Ayurvedic practitioners, the traditionallyand family-trained healers? There are no national data on the number of traditional healers in Nepal but smaller studies indicate widespread forms of practice. A survey of six Village Development Councils representing the various geographical terrains of Gorkha District identified 455 traditional practitioners that are providing the people with the majority of primary health care outside the family, and that are using parts of approximately 250 locally available plant species (150 of which are mentioned in Ayurvedic classics and continue to be used in different Ayurvedic formulations). ${ }^{33}$ Ethnographic evidence from other areas suggests a culture heavily dependent on village healers using medicinal plants.

Traditionally-trained doctors come from three groups. The first and most well-known are those trained by family members with practices going back many generations. These families tend to be high-caste Newari and urbanbased, and many have had family members appointed to Nepal's royal families as doctors. The families often have extensive genealogies of their Ayurvedic practice, with manuscripts on diagnosis, treatment, and medicinal plant pharmacology going back hundreds of years. They tend to keep their medical secrets within the immediate family and rarely have they trained non-family members in the art and science of healing. Some of them will only prescribe medicines they have produced themselves, and will not prescribe medicines either from other pharmacies or from India. Women from these families may also participate in the family healing tradition, though not 'up front' diagnosing and treating patients but rather are found in the background as pharmacists and dispensers of medicine, and as nurses. The professional stature of this exclusive group of baidya is based on both their success as doctors-becoming famous even within expatriate communities for hepatitis A cures-and the reputation of their lineage ancestors.

${ }^{32}$ Pancakarma ('five actions') is a complex treatment for preventive wellness, balance and for chronic illnesses. For 35 days the patient's dosas are balanced through a series of purgings and the consumption of such things as enormous amounts of ghee. Patients at Naradevi, where the treatment is being revived, currently undergo a shortened version to treat musculoskeletal stiffness.

${ }^{33}$ Himalayan Ayurveda Research Institute 1996. 
A second group of non-formally-educated baidya consists of people with apprentice roots that are contemporary, having been trained in families without a long history of Ayurvedic healing, or by non-family members who themselves may or may not come from generations of healers - people such as transient mystics and renowned religious figures. These baidya can be found in rural and urban communities, and their professional stature is based mainly on their success at healing, though some claim the eminence of their teachers as evidence of their own abilities. This group of baidya meets the health care needs of a large segment of the Nepali population, and is more diversified by caste, ethnicity and gender than the first; I have interviewed numerous women and men among them.

A third group of traditional baidya includes the so-called quacks and charlatans, whose short-lived practices dissolve through ill-repute and/or confiscation of their forged documents by the Ayurvedic Medical Council, a body that was legislated 20 years ago and convened for the first time just over ten years ago. There are no data on such practitioners, although the first chair of the Ayurvedic Medical Council barred from practice two people he considered frauds (they were using false certificates) as a direct result of the new power found in the Ayurvedic Medical Council Act regulations, to which we now turn. $^{34}$

\section{In the name of modern science: Controlling Ayurveda rationally}

Current Ayurvedic medical regulation in Nepal can be linked to the privileged position of biomedicine in the developing country, which is heavily supported by policies, budgets and educational curricula, and the power of modern science to shape ideologies of truth and progress. These forces support and extend the state's position that Ayurveda is not a medical science sufficiently verified by the standards of modern science. Even though it is supported by the people, the transmission of Ayurvedic medical knowledge through lineage and non-formal methods is, according to state officials, inadequately systematic and not transparent enough to justify state support. This view echoes one expressed in the late first half of the twentieth century by India's legislators and by Jawaharlal Nehru himself. Then the dominance of a pro-biomedicine

\footnotetext{
${ }^{34}$ An important area of future research would be to evaluate whether patients consider those with falsified documents to be competent and effective healers, and to assess if the Act itself creates an incentive for the traditionally trained to, in fact, create false documents in order to continue practising, as this group would be distinguishable from those with little or no experience.
} 
Congress Party contributed to what Khan characterises as a weak minority resistance to medical regulation that unwittingly served to reproduce distinctions between institutionally-trained physicians and those trained in less formal family and community based traditions, and that never truly challenged the power of modern biomedical science itself. ${ }^{35}$

We see such a divide asserted today in the debate on medical licensing in Nepal. This is between biomedicine and Ayurveda on the one hand, and between different Ayurvedic educational approaches that, as discussed previously, follow urban-rural lines of distinction. One noteworthy difference with the Indian example, though, is that today's advocates of licensing in Nepal are the institutionally-trained Ayurvedic physicians themselves, acting less on behalf of the medical system as a whole and more in favour of the pragmatic advantages that modern forms of knowledge transmission provide to them. According to those involved, this is best explained by economic realities, in which the monopoly historically held by the traditionally trained is effectively broken by medical licensing regulations, thus opening the patient market to state-certified physicians.

This explanation is further evident when we hear the teaching staff at Naradevi Ayurvedic Teaching Hospital in Kathmandu complain that a lack of personnel at the college has led to inadequate knowledge of medicinal plant identification and drug preparation for their students. They admire the greater knowledge of informally and family-trained doctors in plant medicine applications, acquired through long apprenticeships with family members and other traditional teachers. Nonetheless, it is the graduates of these formal programmes who seek to regulate Ayurvedic practice through licensing, as such an action could result in new resources for their programmes to teach ethnobotanical courses, while simultaneously removing control over the field from the traditional physicians. Other opportunities come with medical licensing, and these apparently outweigh the potential loss of botanical and other medical knowledge by marginalising traditional physicians. A second important distinction from the comparative case of mid-twentieth-century India is that resistance to medical licensing is, in Nepal, robust and broad, as we shall see below.

Returning to Nepal's health administration, many officials I have interviewed, themselves from Western scientific and medical backgrounds, do not consider the village practitioners to be true healers, and some have publicly described even formally educated practitioners as 'backward'. One Secretary of Health ended a discussion with me about the Ministry's plans for advancing

\footnotetext{
35 Khan 2006.
} 
Ayurvedic medicine with scepticism about the village healers, suggesting that they should not be called baidya, in spite of the fact that they practise in ways similar to formally-trained doctors. Government officials who characterise Ayurvedic medicine too negatively, however, may lose popular support from a population that cherishes its medical tradition. Dr Ram Yadav twice was appointed Health Minister, but during his first term he was quoted as saying that Ayurveda is like 'the cart being pulled by oxen', whereas allopathic medicine is like a 'supersonic jet'. Equating Ayurveda with a negative characterisation of traditionalism jeopardised his reappointment and he lost his bid, though he was later reappointed. According to some, Minister Yadav displayed a more balanced approach to the two main systems of medicine in Nepal during his second term.

Nonetheless, the official government position on Ayurvedic medicine is that it is a potential risk to the population if fraudulent practices, only speculated and rarely identified, are allowed to exist. Consequently, to answer these concerns and to advance their profession, the Ayurvedic Medical Council, legislated in 1988 and eventually constituted by only formally-trained Ayurvedic practitioners, authored, sponsored and eventually saw the passage of legislation that makes Ayurveda compliant with modern rational standards of medical management.

\section{The Ayurvedic Medical Council Act of 2045/55 (1988/1998) ${ }^{36}$}

In March of 2005 while discussing with me the Ayurvedic Council Act of 1988/1998, Dr Ram Chanda Pandey, Registrar of the Ayurvedic Medical Council, stated: 'We must preserve the knowledge of the traditional practitioners, but we must also protect the people from fraud'. ${ }^{37}$ The Ayurvedic Medical Council Act was first introduced in 1988 and passed ten years later in 1998, the same year members of the Ayurveda Medical Council were appointed. During that period, criticism mounted that Ayurveda was non-scientific and in fact dangerous, fuelled by fears from the allopathic community and international donors that plant-based medicines may be toxic, and combined with concerns that there may be quacks harming the people. Succumbing to these concerns, the Council took up the Act's provisions in ways that likely will have far-reaching implications for the practice of Ayurvedic medicine in Nepal. Despite the absence of empirical evidence of risks from Ayurvedic medicine,

\footnotetext{
${ }^{36}$ The Nepali calendar, called Bikram Sambat, is lunar-based and is 57 years ahead of the Gregorian calendar.

37 Personal communication, 8 March 2005.
} 
the Ayurvedic Medical Council proposed an amendment to the Act that regulates the practice of Ayurvedic medicine in the country by mandating the registration of all practitioners. The amendment recently passed.

According to the Act's amendment, individuals who want to practise Ayurvedic medicine in Nepal must register with the Department of Ayurveda after meeting certain requirements, beginning with a certificate or degree from a recognised institution of Ayurvedic education. Those who do not hold such a degree or certificate must meet very strict conditions in order to continue to treat patients and to manufacture Ayurvedic medicines. According to Article 5.1.1.b of the Act, only those traditional doctors who are 50 years or older may qualify for registration, and they must be able to document, with a letter from their Chief District Officer, that the applicant's family has practised medicine for a minimum of three generations. Equally strict are the limits placed on the production of medicinal plants which, if read literally, would prohibit every Nepali citizen, except those formally trained in Ayurvedic medicine, from producing plant-based medicines. ${ }^{38}$ The traditional baidyas, most of who have not trained in institutions of higher education, now find themselves in open dispute with their professionally-trained colleagues, for they see the new regulation as threatening their very livelihood. ${ }^{39}$

How do we explain the move to disenfranchise traditional healers in a country so widely dependent on them? First, the state's power to shape health care policy in Nepal is influenced by the discourse of modernisation and development, and the implements of scientific medicine, like white laboratory coats and stethoscopes, serve a legitimating truth-function to the newly democratic state. ${ }^{40}$ Under the guise of protecting the population from dangerous medical practices, the state is reaching even further by declaring one kind

38 The section of the Act dealing with drugs reads as follows: ' 6.1 Must receive permission to produce Ayurvedic drugs. 6.1.1. Prescription Ayurveda drugs, as defined and listed by His Majesty's Government (HMG) in published gazette notices, may be produced and prescribed only with the permission of the Ayurvedic Council and approved by the Department of Ayurveda. 6.1.2. As per 6.1.1. Interested persons should apply to the Department of Ayurveda for approval to produce and distribute and/or sell prescribed Ayurveda drugs. 6.1.3 In the case of applications dropped as per 6.1.2, the Department of Ayurveda can take advice from the Ayurvedic Council, and if the applicant is not a registered doctor, the Department can permit the production of drugs under the control and supervision of a registered Ayurvedic doctor. 6.2. Permission to sell Ayurvedic drugs without prescription is prohibited: Prescribed drugs, as listed in published gazette by HMG with the advice of the Ayurvedic Council, cannot be sold without a prescription from registered Ayurvedic doctors.'

39 World Health Organization documents dealing with traditional medicine in Nepal call limiting of practice to registered practitioners only a 'monopoly' over practice (WHO 2001, p. 138).

40 Adams 1998. 
of knowledge - that obtained in institutions of higher education - superior to other forms of knowledge, such as family- and community-based knowledge and one's own experience. Codes of practice become delineated through accredited knowledge only, further strengthening the state's control over health care and removing such control from the purview of local populations.

The central players in this effort are members of the Ayurvedic Medical Council, all highly educated (many with medical degrees in Ayurvedic medicine and surgery from Banaras Hindu University in India) and esteemed Ayurvedic physicians whose original draft of the regulations put the registration age at 40 , and who had proposed more flexible language for lineage practice. However, a coalition of institutionally-trained Ayurvedic and allopathic doctors affiliated with the Congress Party persuaded the Ayurvedic Medical Council, and eventually the full Assembly, to adopt and pass a version of the amendment that raised the age by ten years and strictly defined the lineage requirements. While perhaps not the intended goal, it will certainly be a consequence that traditional systems of medical learning, deemed less systematic and not scientifically proved under a modern medical bureaucracy, will gradually disappear.

\section{Resistance by traditional practitioners}

The traditionally-trained doctors strongly objected to the registration requirements, finding them to be potentially devastating to their practice. For centuries, they claim, their reputations as baidya had been based on experience, knowledge, and family, and it is based on reputation still that Nepalis continue to consult with them about a variety of common and serious illnesses. The lineage and non-formally-trained Ayurvedic physicians who served the palace before the ascension of King Birendra were, of course, protected by the government. But over the past three decades the Nepali state has radically transformed from a closed monarchy to an open democratic society, with a complex bureaucratic structure that includes the Ministry of Health, itself a donor-driven and pro-allopathic institution.

To date, only 12 of the traditionally-trained baidya have registered. The regulations have, in fact, the potential eventually to erase the practice of Ayurvedic medicine by informally- and family-trained healers, for a deadline was set and it has passed; there is no provision for future healers to register. In other words, if one missed the deadline for any number of reasons-being younger than 50, being unable to reach the capital city because of Maoist rebel blockades, being female and therefore uncertain if natal home healers and 
teachers met the generational condition, being unaware of the registration requirements, or being unable to document three generations of healers in the family - the window of opportunity has closed. In the wake of strong protest by a well-known group of traditional practitioners, a compromise was made to further amend the Act and allow for annual registrations, but it failed to pass. The traditional doctors find the 50-year age minimum to be the most restrictive and illogical requirement of the regulation. As the son of one esteemed and now deceased healer put it, a person barely 25 years old can get an MD and become registered. If experience is the issue, then why choose 50 years? 'Why not put it at 80 years of age?', he said sardonically during one of our conversations.

Despite their strong unified objections, traditional practitioners varied in the actions they took in response to the registration requirements. One small group that met the requirements complied by registering. Another and much larger group of older baidya that also met the age and lineage requirements nonetheless ignored the registration mandate; their practices are well-established and they expect not to be fined. A third and relatively small group comprised of people that do not meet the requirements because they are younger than 50 years of age or they lack the lineage history of practice, obtained one-year certificates in Ayurvedic medicine so they might meet the minimal requirement for formally-educated practitioners. The fourth and largest group actively resisted the registration requirements through a public campaign to discredit the Act and its unnamed promulgators, and to appeal to the people and to the Health Ministry to have the Act revoked or modified. Their political agency evolved in response to the legislation, and they strongly asserted their 'right' to practise medicine based on their experience, in spite of lacking formal medical education (some from this group are formally educated in non medical fields).

A subset of this large body of traditionally-trained rural and urban practitioners consequently formed a political action committee and one of their first actions was to file with the apex court a Public Interest Litigation petition with over 100 signatories. The group's leader, Manu Bajracharya, told me that the petition rejected the Ayurvedic Medical Council Act's attempt to standardise Ayurvedic medical education and the mandate to register. However, the apex court recently upheld the Council Act, although according to Council member Dr R. R. Koirala, compromise details may be worked out. As the traditional physicians await the final decision on their petition they continue to provide medical care daily to thousands of Nepalis.

Although the actions individuals took varied, as a group the traditionallytrained practitioners are reacting to the regulations with a forceful unified 
voice. They formed an active professional organisation called the Traditional Ayurvedic Medical Practitioners Association (TAMPA, my acronym) that meets once a month to exchange clinical knowledge, and they hold bi-monthly free clinics in one of the three medieval cities of Kathmandu valley. ${ }^{41}$ Recognising the potential loss of centuries of botanical medical knowledge should the new regulations become fully enforced, the traditional community has responded with a degree of openness about their medical formulas and preparation methods. The sharing of medical knowledge in their monthly symposia is new to the traditional community.

Noteworthy in this response is the productive power of otherwise repressive governmentality, as the state's attempt to control traditional health care providers is resisted by those very providers through the formation of a powerful, public group. ${ }^{42}$ The strong resistance put forth by the traditional Ayurvedic medical practitioners contrasts with that described by Khan for mid-twentieth-century India, where similar regulations by the National Assembly and in particular the Congress Party were met with only weak and somewhat apologetic resistance by practitioners, even when the objectors recognised that it would be the traditionally-trained vaids who would be marginalised. ${ }^{43}$

\section{Conclusions}

One question that remains is whether the state will enforce the medical licensing regulation, and if so, how will enforcement impact people's health? In the immediate future, the practices of traditional baidyas and their patients are not likely to change. Gradually, though, as more BAMS graduates enter the professional market and fewer family-trained baidyas replace the older generation, Ayurvedic medicine in Nepal will become increasingly professionalised in modern ways, more regulated by the state, and its practitioners more likely trained in biomedicine. The first two processes may have a negative impact on health care delivery in Nepal. The state health care bureaucracy tends to inefficiently manage health care resource distribution. Simultaneously increasing the power of biomedicine to dominate medical choice would reduce patient

${ }^{41}$ I first learned of TAMPA while visiting Pashupati Temple on 8 March 2005 for the annual Shivaratri festival, where TAMPA was providing free treatment to Hindu pilgrims.

42 The Association membership itself is unintentionally non-representational in that it comprised almost entirely of urban Newaris from traditional Ayurvedic families - those left out include non Newari baidya from the hills who provide extensive health care to the people of Nepal. The Association claims to represent this group's interests.

43 Khan 2006. 
choices and permanently close traditional paths of medical knowledge transmission. The third change involving an education integrated with training in biomedicine can have a beneficial impact on people's health. Plural medical systems benefit patients and doctors alike. However, insisting on a one-sided approach to integrated medical curricula (allopathic medical curricula are not required to have an Ayurvedic component), while simultaneously limiting those who may practise Ayurvedic medicine and those who may use and share medicinal plant resources, are actions proceeding in a direction opposite to the goal of plural medicine.

Pressure on the Ministry of Health to regulate Ayurvedic medicine is an outcome of the goal to modernise health care in Nepal as an important implementation of progress in the country as a whole. The desire for a modern country is promulgated in the country's short- and long-term development plans, its educational system, and the promotion of and participation in consumer culture. ${ }^{44}$ It is not modernity that is debated in the confrontations over Ayurvedic medical licensing, even though the traditional/modern medicine divide is resurrected and exploited at times by health care personnel, as we saw above with the case of the Minister of Health. Indeed, many Ayurvedic physicians, traditionally and formally trained, assert that Ayurveda is modern, and its global embrace strengthens their claim. Rather, as I have argued, it is knowledge and ultimately power that is at the heart of the controversy, namely the organsation and the transmission of knowledge on the one hand, how that knowledge is established and legitimated (through science practices), and who will own that knowledge and put it to use for economic gain and society's welfare. We see this struggle over the circulation of knowledge evident in the state's increasing control over medical education in the past few decades, in how the physicians view science in relation to Ayurveda, and in the last minute push to wrest control over the patient market away from the monopoly held by traditional doctors and into the hands of the formally trained. That the state was leveraged on behalf of the institutionally trained is clear.

Khan describes for India the history of achieving a similar goal begun during the first half of the twentieth century, and to a certain extent continued until today. ${ }^{45}$ The Indian Assembly under the control of the Indian National Congress Party met only a modicum of resistance from the Ayurvedic community to its efforts to bring Indias health care system in line with the standards of (British) scientific biomedicine (2788-91). Other studies of contemporary Ayurvedic practices in India describe a variety of positions that

\footnotetext{
44 Liechty 2002.
}

45 Khan 2006. 
physicians take to biomedicine, including a post-colonial Ayurvedic revivalism partly connected to Indian cultural revivalism. ${ }^{46}$ In contrast, Nepal has no colonial history from which its professional classes seek a new-found postcolonial identity, and it has tended to embrace traditionalism in a limited way within ethnic minority rights movements and highly controversial and ultimately unsuccessful political movements to preserve the monarchy.

The people of Nepal have not felt the need to revive cultural practices they regard as threatened by foreign powers. On the contrary, Nepal's newly promulgated post-monarchy constitution attempts to shed remnants of the past such as caste and ethnic hierarchy, rather than continue to sustain what to the majority has become the untenable notion of a Hindu kingdom. The general trend in the first and second post-revolutionary periods in Nepal is the evolution of a population that desires many aspects of a modern society, such as increased consumer products, elite education, democratic representation, and public health improvements, but one that has also accepted the idea of a plural society and a plural medical landscape. In fact, the professional regulations described here spring from a minority position that nonetheless wielded sufficient power to pass legislation that contradicts values of progress the people support.

Traditional medicine provides health care to the majority of the people of Nepal, and it continues to do so in spite of strong efforts by the government to provide allopathic medicine in even remote mountain regions (e.g. immunisation programmes) and by national and international pharmaceutical companies to proliferate drugs on the market. Ayurvedic medicine is popular and efficacious, is increasingly sought by college students as a medical education choice (for the first time in a decade, newly- matriculated BAMS students at Naradevi chose Ayurveda as their first choice in medical education, reversing a trend of students enrolling in Naradevi's programme after failing to gain admission to an allopathic medical programme), and is a potential source of revenue for the struggling nation if medicinal plant development is allowed to proceed so that the country can reduce its dependency on Indian Ayurvedic drugs.

While regulations such as professional registration might ensure that only competent health care providers are permitted to treat the ill, the Nepali people believe policy is most effectively and beneficially developed when a representational body, willing to dissent and discuss, presides over the process. After all, they have waged two revolutions and one insurgency in 18 years to give everyone a greater voice in governance. The Ayurvedic medical licensing law did not proceed in a representational manner. As a consequence of

${ }^{46}$ Langford 2002. 
non-consultative and top-down policy development, there is the potential loss of enormous healing resources should the non-formally trained baidya, with their vast wealth of medicinal plant knowledge, be prohibited from practising.

\section{Acknowledgements}

The research on which this article is based was funded in part by the College of Liberal Arts and Humanities Development Summer Grants and a Professional Improvement Leave Grant, Auburn University; a Fulbright Senior Scholar Fellowship; and, a Research Initiation Grant, Division of Sponsored Research and four months of research leave, Dorothy F. Schmidt College of Arts and Letters, Florida Atlantic University. I would like to acknowledge the kind and enduring support of Nepali colleagues and friends: Lokendra Man Singh (deceased), Sarita Shrestha, Rishi Ram Koirala, Narendra Nath Tiwari, Om Gurung, Durga Sob, Siddhi Gopal Vaidya (deceased), Meena Acharya, Ram Chhetri, Madan Bahadur Rokaya, Gagan Jung Bahadur Singh (deceased), Dil Bahadur Malla and Manu Bajracharya. The help of research assistants Bhupendra N. Khaniya and Bijaya Bista in Nepal and Colleen Supanich at Florida Atlantic University in the United States was invaluable. North American colleagues who have provided thoughtful insights in discussing the ideas here include Judith Justice, Lynn Kwiatkowski, Stacy Pigg, and Sienna Craig. I thank two anonymous reviewers from Asian Medicine for suggesting important clarifications.

\section{References}

Adams V. 1988, 'Modes of Production and Medicine: An Examination of the Theory in Light of Sherpa Medical Traditionalism', Social Science and Medicine, 27: 505-13.

— 1998, Doctors for Democracy, Cambridge, MA: Oxford University Press.

Anderson W. 2003. 'The Natures of Culture: Environment and Race in the Colonial Tropics', in Greenough P. and A. Tsing (eds), Nature in the Global South: Environmental Projects in South and Southeast Asia, Durham, NC: Duke University Press, 29-46.

Berlin I. 2001, Against the Current: Essays in the History of Ideas, Princeton, NJ: Princeton University Press.

Bode M. 2006, 'Taking Traditional Knowledge to the Market: The Commoditization of Indian Medicine', Anthropology and Medicine, 13:3, 225-36.

Burghart R. 1984, 'The Tisiyahi Klinik: A Nepalese Medical Centre in an Intracultural Field of Relations', Social Science and Medicine, 18: 589-98.

Cameron M. 1986, 'Ethnomedicine and Epidemics: A Case Study of Measles in Nepal', unpublished manuscript, Annual South Asian Conference, Madison, WI, 7-9 November. 
2009a forthcoming, 'Untouchable Healing: A Dalit Ayurvedic Doctor from Nepal Suffers his Country's Ills', Medical Anthropology.

$2009 b$ forthcoming, 'Healing Landscapes: Sacred and Rational Nature in Nepal's Ayurvedic Medicine', in Arjun Guneratne (ed.), Culture, Nature and Society in the Himalaya: Symbolic Ecologies, Routledge.

Chaudhury R. R. 2001, Traditional Medicine, WHO, SEARO.

Des Chene M. 1996, 'In the Name of Bikas', Studies in Nepali History and Society, 1: 259-70.

Dixit H. 1995, The Quest for Health, Kathmandu, Nepal: Educational Enterprise Ltd.

Durkin M. 1982, 'Ayurveda in Nepal: A Medical Belief System in Action', unpublished PhD dissertation, University of Michigan.

Ernst W. (ed.) 2002, Plural Medicine, Tradition and Modernity: Historical and Contemporary Perspectives: Views from Below and from Above, 1800-2000, New York: Routledge.

Himalayan Ayurveda Research Institute 1996, 'Project Report: Medicinal Plants and Traditional Medical Practice in Gorkha District', Kathmandu, Nepal: Gorkha Development Project/GTZ. Justice J. 1986, Policies, Plans and People: Culture and Health Development in Nepal, Berkeley: University of California Press.

Kanel K. R. 2000, 'Sustainable Management of Medicinal and Aromatic Plants in Nepal: A Strategy', a Study Commissioned by IDRC/SARO, Medicinal and Aromatic Plants Program in Asia (MAPPA): New Delhi, India.

Khan S. 2006, 'Systems of Medicine and Nationalist Discourse in India: Towards "New Horizons" in Medical Anthropology and History', Social Science and Medicine, 62: 2786-97.

Langford J. 2002, Fluent Bodies: Ayurvedic Remedies for Postcolonial Imbalance, Durham: Duke University Press.

Leslie C. 1976a, 'The Ambiguities of Medical Revivalism in Modern India', in Leslie C. (ed.), Asian Medical Systems: A Comparative Study, Berkeley: University of California Press, 356-67.

— 1976b, 'Introduction', in Leslie C. (ed.), Asian Medical Systems: A Comparative Study, Berkeley: University of California Press, 1-12.

— 1992, 'Interpretations of Illness: Syncretism in Modern Ayurveda', in Leslie C. and A. Young (eds), Paths to Asian Medical Knowledge, Berkeley: University of California Press, 177-208.

Liechty M. 2002, Suitably Modern: Making Middle-Class Culture in a New Consumer Society, Princeton: Princeton University Press.

Lock M. and M. Nichter 2002, 'Introduction: From Documenting Medical Pluralism to Critical Interpretations of Globalized Health Knowledge, Policies, and Practices', in Nichter M. and M. Lock (eds), New Horizons in Medical Anthropology: Essays in Honour of Charles Leslie, London: Routledge, 1-34.

Naraindas H. 2006, 'Of Spineless Babies and Folic Acid: Evidence and Efficacy in Biomedicine and Ayurvedic Medicine', Social Science and Medicine, 62: 2658-79.

Nepal Development Forum 2002, 'Medium-Term Expenditure Framework, 2002-2005', Kathmandu, Nepal: His Majesty's Government.

Nichter M. 1981, 'Negotiation of the illness Experience: The Influence of Ayurvedic Therapy on the Psychosocial Dimension of Illness', Culture, Medicine and Psychiatry, 5: 5-24.

— 2001, 'The Political Ecology of Health in India: Indigestion as Sign and Symptom of Defective Modernization', in Connor L. H. and G. Samuel (eds), Healing Powers and Modernity: Traditional Medicine, Shamanism, and Science in Asian Societies, Westport, CT: Bergin and Garvey, 85-108.

Nisula T. 2006, 'In the Presence of Biomedicine: Ayurveda, Medical Integration and Health Seeking in Mysore, South India', Anthropology and Medicine, 13, 3: 207-24.

Parker B. 1988, 'Ritual Coordination of Medical Pluralism in Highland Nepal: Implications for Policy', Social Science and Medicine, 27: 919-25. 
Pigg S. L. 1992, 'Inventing Social Categories Through Place: Social Representations and Development in Nepal', Comparative Studies in Society and History, 34: 491-513.

Sharma R. K. and D. Bhagwan 1998, Carakasamhita, Varanasi, India: Chowkhamba Sanskrit Series Office.

Sharma S. 1983 [1929], The System of Ayurveda, New Delhi, India: Neeraj Publishing House.

Shrestha N. 1995, 'Becoming a Development Category', in Crush J. (ed.), Power of Development, London and New York: Routledge, 266-77.

Singh L. M. n.d., 'Integrated Health Care System: A Way out for Global Welfare', unpublished manuscript.

Singh L. M. and B. N. Khaniya n.d., 'Ayurveda: Cultural, Medical Heritage', unpublished manuscript.

Stone L. 1976, 'Concepts of Illness and Curing in a Central Nepal Village', Contributions To Nepalese Studies, 3: 55-80.

— 1986, 'Primary Health Care for Whom? Village Perspectives from Nepal', Social Science and Medicine, 22, 3: 293-302.

White D. 1996, The Alchemical Body, Chicago: University of Chicago Press.

World Health Organization 2001, Legal Status of Traditional Medicine and Complementary/Alternative Medicine: A Worldwide Review, Geneva, Switzerland: World Health Organization.

Wujastyk D. 2003, The Roots of Ayurveda, London: Penguin Books.

Zimmerman F. 1987, The Jungle and the Aroma of Meats: An Ecological Theme in Hindu Medicine, Berkeley: University of California Press.

Zysk K. 1991, Asceticism and Healing in Ancient India: Medicine in the Buddhist Monastery, New York: Cambridge University Press. 